\title{
Personal, behavioral, and perceived environmental factors associated with late-life depression in older men and women
}

This article was published in the following Dove Press journal:

Psychology Research and Behavior Management

\author{
Chien-Yu Lin ${ }^{1,2}$ \\ Bohyeon $\mathrm{Kim}^{3}$ \\ Yung Liao ${ }^{4, *}$ \\ Jong-Hwan Park ${ }^{3, *}$ \\ 'Graduate School of Sport Sciences, \\ Waseda University, Tokorozawa, Japan; \\ ${ }^{2}$ Institute of Health Behaviors and \\ Community Sciences, College of Public \\ Health, National Taiwan University, \\ Taipei, Taiwan; ${ }^{3}$ Health Convergence \\ Medicine Research Group, Biomedical \\ Research Institute, Pusan National \\ University Hospital, Busan, Korea; \\ ${ }^{4}$ Department of Health Promotion and \\ Health Education, National Taiwan \\ Normal University, Taipei, Taiwan \\ *These authors contributed equally to \\ this work
}

Introduction: Previous investigations on factors associated with depression were highly focused on personal characteristics and health behaviors; however, few studies used an ecological perspective on the issue, much less on sex differences. This study examined the factors associated with depression, including any sex differences.

Methods: A total of 1025 Taiwanese adults older than 65 years were recruited. Their personal demographics, lifestyle behaviors, and perceived environmental factors were obtained through a telephone-based survey. The multiple factors associated with depression in older adults were examined using logistic regression analyses.

Results: Fully logistic regression analyses revealed that poor self-rated health (odds ratio $=2.54$ ) was correlated with a greater likelihood of depression. Aside from poor self-rated health, being older, sufficient leisure time spent in walking, and perceptions of a safe environment were associated with lower risks of depression in older men, whereas having hypertension and excessive TV viewing were associated with higher risks of depression in older women.

Conclusion: Apart from self-rated health, sex differences in the associations of factors such as leisure-time walking, TV watching, and safe traffic environment with depression were observed among older adults. Strategies applied for geriatric depression prevention should take into consideration different sex group.

Keywords: geriatric depression, older adults, multiple factors

\section{Background}

Depression is a major cause of life impairment worldwide. Its symptoms may cause negative consequences such as disability and suicide; ${ }^{1}$ it also results in economic burden, including the costs related to mental health services and the loss of productivity derived from depression. ${ }^{2}$ A meta-analysis, mostly from the United States and Europe, showed a pooled prevalence of depressive disorders was $17.1 \%$ among community-based older adults aged 75 years and above. ${ }^{3}$ A longitudinal study using national representative population for older adults aged 65 and above showed the incidence rate of depression was 19.7\% across four years (2000-2003) in Taiwan. ${ }^{4}$ There was evidence showing that there were sex differences in depression. For example, a study comprised 23 European countries found female adults reported higher level of depression than male adults. ${ }^{5}$ Another study from Taiwan also reported that the prevalence of depression among older adults was higher in women $(12.4 \%)$ than in men $(7.8 \%){ }^{6}$ While considering older adults aged 65 and
Correspondence: Yung Liao Department of Health Promotion an Health Education, National Taiwan Tel +88627 734 I 722

Email liaoyung@ntnu.edu.tw

Jong-Hwan Park

Health Convergence Medicine Research

Group, Biomedical Research Institute,

Pusan National University Hospital,

Busan, Korea

Tel +82 I06 $228 \quad 1485$

Email jpark@pnuh.co.kr 
above account for $14.6 \%$ of a total population in Taiwan, ${ }^{7}$ there is an urgent need to identify the multiple factors associated with depression among the older population in order to develop effective prevention strategies.

An effective strategy of improving early detection is to investigate older adults' characteristics and identify the atrisk population. Previous research has indicated some personal characteristics (eg, sex and health status) ${ }^{8,9}$ and behavioral factors (eg, the level of physical activity) ${ }^{10}$ were associated with risk of depressive symptoms. However, macro-level depression prevention should also consider other modifiable lifestyle factors such as environmental attributes according to ecological perspectives ${ }^{11}$ but few studies have investigated on the environmental factors. Identifying the associations of environmental factors with depression is critical for developing future interventions. Older adults tend to spend most of their time near their neighborhood due to their declined mobility. ${ }^{12}$ Therefore, if the neighborhood environment is not safe, it may cause sources of chronic stressor and fears. ${ }^{13}$ Limited evidence showed that poor environmental safety is associated with higher odds of depression in older adults; ${ }^{14,15}$ however, whether there were sex differences still need further investigation. This study examined the associations of multiple levels of factors, including personal, behavioral, and environmental factors, with depression among older adults, with a particular focus on sex differences.

\section{Materials and methods}

\section{Participants}

The participants in the present study were recruited for a cross-sectional population-based survey, which was conducted in November 2016 in Taiwan through a computerassisted telephone interviewing system. In that year, Taiwan was estimated to have a population of $23,539,816$ and a total of $13.2 \%$ were the target population aged 65 years and above $(\mathrm{N}=3,106,105) .{ }^{16}$ The required sample size for the present study was calculated to be 1025 older adults with a $95 \%$ confidence level and a 3\% confidence interval. These participants were randomly sampled by their residual areas in the beginning, and then by their sex and age group. All the interviewers had experience in administering telephone surveys and had been trained in using a standardized form to ask questions before the survey started. Participants were not offered any rewards for participating, and verbal informed consent was obtained before the start of each telephone interview. The study protocols were reviewed and approved by the Ethics Committee of National Taiwan Normal University (201605HM006).

\section{Outcome variable}

Geriatric Depression Scale-4 (GDS-4) is a short-form depression scale which has an acceptable level of internal consistency (Cronbach's alpha $=0.55$ ). ${ }^{17}$ The questionnaire was suggested to be used in screening depression in older adults ${ }^{17}$ and was used in telephone survey. ${ }^{18}$ In the present study, depression was measured using the Chinese version of the GDS-4. The questionnaire was examined as a high sensitivity and specificity (area under the curve $=0.76$ ) instrument and could be used to assess depression in older Taiwanese adults. ${ }^{19}$ Participants were required to state their mental status over the past week in terms of the following questions from the four-item version: (1) "Are you basically satisfied with your life?"; (2) "Do you feel that your life is empty?"; (3) "Are you afraid that something bad is going to happen to you?"; and (4) "Do you feel happy most of the time?" Each question was dichotomized into "yes" or "no." The total score for the GDS-4 ranges from 0 to 4 (answering "yes" to questions 1 and 4 and "no" to questions 2 and 3 counted as 1 point each). When different cutoff points were compared, the sensitivity and specificity for the GDS-4 were, respectively, $89 \%$ and $65 \%$ (cutoff point $0 / 1$ ) and $61 \%$ and $81 \%$ (cutoff point $1 / 2$ ). ${ }^{17}$ In the present study, we defined older adults with depression as a score of more than 0 point due to the improved sensitivity and specificity.

\section{Personal factors}

\section{Sociodemographic variables}

The sociodemographic variables covered in the present study were sex, age (continuous), residential area, education, occupation, marital status, accommodation status, and body mass index (BMI; dividing self-reported weight by the square of height). Residential area was classified into "metropolitan" and "nonmetropolitan." Educational status was categorized into "high school degree or lower" and "university degree or higher." Occupational type was divided into "not full-time job" and "full-time job," and marital status was divided into "married" and "unmarried" (including widowed and divorced). Accommodation status was categorized into "living with others" and "living alone." BMI was divided into "non-overweight $(<24$ $\left.\mathrm{kg} / \mathrm{m}^{2}\right)$ " and "overweight $\left(\geq 24 \mathrm{~kg} / \mathrm{m}^{2}\right)$ " according to the definitions provided by the Health Promotion 
Administration, Ministry of Health and Welfare of Taiwan. $^{20}$

\section{Diseases and self-rated health status}

The most common chronic diseases among older adults in Taiwan are hypertension, diabetes mellitus, and cardiovascular disease. Therefore, participants were asked according to the following questions: "Have you ever been diagnosed by a doctor as having the following diseases, or are you currently taking medication for them?" Each question (regarding hypertension, diabetes mellitus, and cardiovascular disease) was divided into three options: "yes," "no," and "unknown." A choice of "unknown" was categorized as missing data. An additional question regarding self-rated health status was also included, with answers divided into "good" and "poor."

\section{Behavioral factors}

\section{Leisure time walking and TV viewing}

Leisure time spent in walking was acquired using the Taiwanese version of the International Physical Activity Questionnaire (IPAQ), long version. The IPAQ is suitable for and widely used in telephone-based surveys among middle-aged-to-older adults. ${ }^{21,22}$ The test-retest reliability of the IPAQ in the present study was 0.78 and the criterion validity compared with accelerometers was $0.31-0.41 .^{23}$ Leisure time spent in walking was calculated by multiplying the frequency $(\mathrm{d} / \mathrm{wk})$ by the duration of leisure time (mins/d), according to the Kolmogorov-Smirnov test, and the resulting distribution was skewed. On the basis of the Global Recommendations on Physical Activity for Health for older adults, ${ }^{24,25}$ this variable was categorized into "sufficient ( $\geq 150 \mathrm{mins} / \mathrm{wk}$ )" and "insufficient ( $<150 \mathrm{mins} / \mathrm{wk})$."

Time spent in watching TV or videos was obtained from the Measure of Older Adults' Sedentary Time questionnaire. The item has an acceptable level of test-retest reliability (intraclass correlation coefficient $=0.69$; Spearman $\rho=0.67$ ) in the version translated into Chinese, and can be used to investigate sedentary behavior among Taiwanese older adults. ${ }^{21,26}$ The sum of TV viewing time was dichotomized based on $2 \mathrm{hrs} / \mathrm{d}$, which has been reported as a threshold for health risks. ${ }^{27,28}$ Thus, the variable was divided into "high TV viewing time $(\geq 2$ hrs/d)" and "low TV viewing time ( $<2 \mathrm{hrs} / \mathrm{d})$."

\section{Alcohol use, smoking, and diet}

Habitual health behaviors such as alcohol use, smoking, and having a balanced diet (three servings of vegetables and two servings of fruits) were also recorded, in accordance with the literature. ${ }^{29-31}$ Each question was dichotomized into "yes" and "no."

\section{Perceived environmental factors}

Perceived neighborhood environmental factors were determined using the Taiwanese version of the International Physical Activity Questionnaire Environmental Module (IPAQ-E). The questionnaire was developed to investigate the relationship between these environmental factors and walking or cycling in diverse countries, including Asian countries. $^{32}$ The IPAQ-E questionnaire was used in a previous study on the association between perceptions of the environment and other health behaviors. ${ }^{33}$ Two out of the 17 items in the IPAQ-E questionnaire comprised the variables investigated in this study: (1) safety from crime at night and (2) traffic safety, in accordance with the literature. ${ }^{14,34}$ Other items that were not empirically associated with depression were excluded. As in previous studies, ${ }^{22,35}$ all of the three factors were included using a 4-point Likert scale and transformed into binary items, recorded as "agree" (strongly agree and somewhat agree) and "disagree" (somewhat disagree and strongly disagree).

\section{Statistical analysis}

The data of 1025 older Taiwanese adults who completed the questionnaire for the present study were analyzed. Chisquared tests were used to evaluate the proportional differences in variables by sex, and logistic regression models were used to analyze the categorical outcome variables and estimate the odds ratios (ORs) of depression. This analysis examined all of the participants as one group first, and then stratified them by sex. Adjusted ORs and 95\% confidence intervals (CIs) were calculated for each variable. The data were analyzed in 2016 using SPSS version 23.0 (IBM Corp, Armonk, NY), and the level of significance was set at 0.05 .

\section{Results}

\section{Participant characteristics}

A total of 1025 older adults completed this survey, with a response rate of 30.3\%. Participants' ages ranged from 65 to 94 years (mean age $=72.35$ years; standard deviation=6.14). The characteristics of the participants were compared overall and by sex. As shown in Table 1, in this sample, men were older, more likely to live in nonmetropolitan areas, have a higher level of education and a full-time job, be married and overweight, be a drinker and 
Table I Participant characteristics overall and by sex $(n=1025)$

\begin{tabular}{|c|c|c|c|c|}
\hline Variables & Total & Men & Women & $p$-value \\
\hline n (\%) & 1025 & $522(50.9 \%)$ & $503(49.1 \%)$ & \\
\hline \multicolumn{5}{|l|}{ Personal factors } \\
\hline Age (year) & & & & $0.001 *$ \\
\hline $65-74$ & 677 (66.0\%) & $319(61.1 \%)$ & $358(71.2 \%)$ & \\
\hline $75+$ & $348(34.0 \%)$ & $203(38.9 \%)$ & $145(28.8 \%)$ & \\
\hline Residential area & & & & $0.003 *$ \\
\hline Metropolitan & $505(49.3 \%)$ & $233(44.6 \%)$ & $272(54.1 \%)$ & \\
\hline Non-metropolitan & $520(50.7 \%)$ & $289(55.4 \%)$ & $231(45.9 \%)$ & \\
\hline Educational status & & & & $<0.00 I^{* *}$ \\
\hline High school degree and lower & 731 (7I.3\%) & $330(63.2 \%)$ & $40 \mathrm{I}(79.7 \%)$ & \\
\hline University and higher & $294(28.7 \%)$ & $192(36.8 \%)$ & $102(20.3 \%)$ & \\
\hline Occupational type & & & & $0.018^{*}$ \\
\hline Not full-time & $920(89.8 \%)$ & 457 (87.5\%) & $463(92.0 \%)$ & \\
\hline Full-time & $105(10.2 \%)$ & 65 (I2.5\%) & $40(8.0 \%)$ & \\
\hline Marital status & & & & $<0.00 I^{* *}$ \\
\hline Not married & $234(22.8 \%)$ & 85 (16.3\%) & $149(29.6 \%)$ & \\
\hline Married & 791 (77.2\%) & 437 (83.7\%) & $354(70.4 \%)$ & \\
\hline Accommodation status & & & & 0.382 \\
\hline Living alone & $139(13.6 \%)$ & $66(12.6 \%)$ & 73 (14.5\%) & \\
\hline Living with others & $886(86.4 \%)$ & $456(87.4 \%)$ & $430(85.5 \%)$ & \\
\hline BMI & & & & $0.022 *$ \\
\hline Non-overweight & 599 (58.4\%) & $287(55.0 \%)$ & $312(62.0 \%)$ & \\
\hline Overweight & $426(41.6 \%)$ & 235 (45.0\%) & 191 (38.0\%) & \\
\hline Hypertension & & & & 0.588 \\
\hline Yes & 453 (44.2\%) & 235 (45.0\%) & $218(43.3 \%)$ & \\
\hline No & $572(55.8 \%)$ & $287(55.0 \%)$ & $285(56.7 \%)$ & \\
\hline Diabetes mellitus & & & & 0.244 \\
\hline Yes & 190 (I8.5\%) & 104 (19.9\%) & $86(17.1 \%)$ & \\
\hline No & $835(81.5 \%)$ & $418(80.1 \%)$ & $417(82.9 \%)$ & \\
\hline Cardiovascular diseases & & & & 0.138 \\
\hline Yes & 173 (16.9\%) & 97 (I8.6\%) & 76 (I5.1\%) & \\
\hline No & $852(83.1 \%)$ & $425(81.4 \%)$ & $427(84.9 \%)$ & \\
\hline Self-rated health status & & & & 0.138 \\
\hline Good & $830(81.0 \%)$ & $432(82.8 \%)$ & $398(79.1 \%)$ & \\
\hline Poor & 195 (19.0\%) & $90(\mathrm{I} 7.2 \%)$ & 105 (20.9\%) & \\
\hline Depression & & & & 0.535 \\
\hline Yes & 345 (33.7\%) & I7I (32.8\%) & $174(34.6 \%)$ & \\
\hline No & $680(66.3 \%)$ & $35 \mathrm{I}(67.2 \%)$ & 329 (65.4\%) & \\
\hline \multicolumn{5}{|l|}{ Behavioral factors } \\
\hline Leisure-time walking & & & & 0.052 \\
\hline Sufficient & $682(66.5 \%)$ & $362(69.3 \%)$ & $320(63.6 \%)$ & \\
\hline Insufficient & $343(33.5 \%)$ & $160(30.7 \%)$ & $183(36.4 \%)$ & \\
\hline
\end{tabular}

(Continued) 
Table I (Continued).

\begin{tabular}{|c|c|c|c|c|}
\hline Variables & Total & Men & Women & $p$-value \\
\hline Television viewing & & & & 0.775 \\
\hline Low & $508(49.6 \%)$ & $26 \mid(50.0 \%)$ & $247(49.1 \%)$ & \\
\hline High & $517(50.4 \%)$ & $26 \mid(50.0 \%)$ & $256(50.9 \%)$ & \\
\hline Alcohol use & & & & $<0.00 I^{* *}$ \\
\hline Yes & $113(11.0 \%)$ & 98 (I8.8\%) & $15(3.0 \%)$ & \\
\hline No & 912 (89.0\%) & $424(81.2 \%)$ & $488(97.0 \%)$ & \\
\hline Smoking status & & & & $<0.00 I^{* *}$ \\
\hline Yes & $75(7.3 \%)$ & $7 \mid(13.6 \%)$ & $4(0.8 \%)$ & \\
\hline No & $950(92.7 \%)$ & $45 \mathrm{I}(86.4 \%)$ & 499 (99.2\%) & \\
\hline Diet behavior & & & & 0.427 \\
\hline Yes & 819 (79.9\%) & $412(78.9 \%)$ & 407 (80.9\%) & \\
\hline No & $206(20.1 \%)$ & $110(21.1 \%)$ & $96(19.1 \%)$ & \\
\hline \multicolumn{5}{|l|}{ Perceived environmental factors } \\
\hline Safety from crimes at night & & & & $0.036 *$ \\
\hline Safe & $851(83.0 \%)$ & $446(85.4 \%)$ & 405 (80.5\%) & \\
\hline Not safe & $174(17.0 \%)$ & $76(14.6 \%)$ & $98(19.5 \%)$ & \\
\hline Traffic safety & & & & 0.708 \\
\hline Safe & $683(66.6 \%)$ & $345(66.1 \%)$ & 338 (67.2\%) & \\
\hline Not safe & 342 (33.4\%) & 177 (33.9\%) & $165(32.8 \%)$ & \\
\hline
\end{tabular}

Notes: $* P<0.05, * * P<0.001$.

Abbreviation: BMI, body mass index.

a smoker, and feel safer at night. The prevalence of depression among all the survey participants in this sample was $33.7 \%$, and women $(34.6 \%)$ had a higher prevalence of depression than men $(32.8 \%)$.

\section{Multiple factors associated with depression}

Logistic regression analysis was performed on the studied variables for depression. The results yielded four significant overall associations of depression. Older adults who had poor self-rated health $(\mathrm{OR}=2.54,95 \% \mathrm{CI}=1.82-3.54)$ were associated with a higher risk of depression (Table 2).

Table 2 also reveals the significant factors associated with depression by sex. Older men who had poor self-rated health $(\mathrm{OR}=2.68,95 \% \mathrm{CI}=1.63-4.41)$ were more likely to be depressed. By contrast, those who were older ( $\mathrm{OR}=0.96,95 \% \mathrm{CI}=0.93-0.99)$, spent more leisure time in walking $(\mathrm{OR}=0.56,95 \% \mathrm{CI}=0.36-0.86)$, and felt safer from traffic $(\mathrm{OR}=0.61,95 \% \mathrm{CI}=0.41-0.91)$ were less likely to be depressed. Furthermore, older women who had hypertension $(\mathrm{OR}=1.64,95 \% \mathrm{CI}=1.11-2.45)$, had poor self-rated health $(\mathrm{OR}=3.03,95 \% \mathrm{CI}=1.87-4.91)$, and spent excessive time ( $\geq 2 \mathrm{hrs} / \mathrm{d})$ on watching TV $(\mathrm{OR}=1.75,95 \% \mathrm{CI}=1.19-2.58)$ were more likely to be depressed.

\section{Discussion}

The results reveal that in addition to self-rated health status, differences were observed between older men and women in terms of the personal, behavioral, and perceived environmental factors associated with depression, similar to the findings of a previous study. ${ }^{10}$ Being married, sufficient leisure time spent in physical activity, and perceptions of a safe environment were associated with lower risks of depression in older men, whereas excessive TV viewing and having hypertension were associated with higher risks of depression in older women. The findings suggest that sex differences should be considered when developing effective approaches for depression prevention in older adults.

The findings of this study demonstrated that self-rated health was negatively associated with depression, regardless of sex. This supports the findings of previous studies ${ }^{36,37}$ and implies that participants' experiences of their own health predict subsequent emotional features. Future interventions 
Table 2 Multiple factors associated with depression by sex

\begin{tabular}{|c|c|c|c|}
\hline \multirow[t]{2}{*}{ Variables } & Total & Men & Women \\
\hline & OR $(95 \% \mathrm{Cl})$ & OR (95\% Cl) & OR $(95 \% \mathrm{Cl})$ \\
\hline \multicolumn{4}{|l|}{ Personal factors } \\
\hline Age (year) & $0.98(0.96-1.00)$ & $0.96(0.93-0.99) *$ & $1.01(0.97-1.04)$ \\
\hline \multicolumn{4}{|l|}{ Residential area } \\
\hline Metropolitan & $0.97(0.74-1.26)$ & I.II (0.76-I.64) & $0.88(0.60-1.28)$ \\
\hline Non-metropolitan & 1.00 & 1.00 & 1.00 \\
\hline \multicolumn{4}{|l|}{ Educational status } \\
\hline High school degree and lower & $1.15(0.85-1.57)$ & $1.16(0.76-1.75)$ & $1.06(0.65-1.7 I)$ \\
\hline University and higher & 1.00 & 1.00 & 1.00 \\
\hline \multicolumn{4}{|l|}{ Occupational type } \\
\hline Not full-time & $0.88(0.57-1.37)$ & $1.20(0.67-2.16)$ & $0.59(0.30-1.18)$ \\
\hline Full-time & 1.00 & 1.00 & 1.00 \\
\hline \multicolumn{4}{|l|}{ Marital status } \\
\hline Not married & 1.00 & 1.00 & 1.00 \\
\hline Married & $0.83(0.58-1.19)$ & $0.56(0.31-1.02)$ & $1.06(0.67-1.70)$ \\
\hline \multicolumn{4}{|l|}{ Accommodation status } \\
\hline Living alone & $1.14(0.74-1.76)$ & $\mathrm{I} .68(0.86-3.30)$ & $0.72(0.39-1.33)$ \\
\hline Living with others & 1.00 & 1.00 & 1.00 \\
\hline \multicolumn{4}{|l|}{ BMI $\left(\mathrm{kg} / \mathrm{m}^{2}\right)$} \\
\hline Non-overweight(<24) & $1.13(0.86-1.48)$ & $1.02(0.69-1.50)$ & $1.31(0.88-1.95)$ \\
\hline Overweight $(\geqq 24)$ & 1.00 & 1.00 & 1.00 \\
\hline \multicolumn{4}{|l|}{ Hypertension } \\
\hline Yes & $1.20(0.9 \mid-1.57)$ & $0.86(0.58-1.27)$ & $1.64(1.11-2.45)^{*}$ \\
\hline No & 1.00 & 1.00 & 1.00 \\
\hline \multicolumn{4}{|l|}{ Diabetes mellitus } \\
\hline Yes & $1.08(0.77-1.52)$ & I.48 (0.92-2.37) & $0.65(0.38-1.10)$ \\
\hline No & 1.00 & 1.00 & 1.00 \\
\hline \multicolumn{4}{|l|}{ Cardiovascular diseases } \\
\hline Yes & $0.86(0.60-1.25)$ & $1.06(0.64-1.75)$ & $0.63(0.35-1.13)$ \\
\hline No & 1.00 & 1.00 & 1.00 \\
\hline \multicolumn{4}{|l|}{ Self-rated health status } \\
\hline Good & 1.00 & 1.00 & 1.00 \\
\hline Poor & $2.54(1.82-3.54)^{* * *}$ & $2.68(I .63-4.4 I)^{* * *}$ & $3.03(1.87-4.91)^{* * *}$ \\
\hline \multicolumn{4}{|l|}{ Behavioral factors } \\
\hline \multicolumn{4}{|l|}{ Leisure-time walking (mins/week) } \\
\hline Sufficient $(\geqq 150)$ & $0.83(0.62-1.11)$ & $0.56(0.36-0.86)^{* *}$ & $1.24(0.8 \mathrm{I}-1.90)$ \\
\hline Insufficient $(<150)$ & 1.00 & 1.00 & 1.00 \\
\hline \multicolumn{4}{|l|}{ Television viewing } \\
\hline Low & 1.00 & 1.00 & 1.00 \\
\hline High & $1.27(0.97-1.65)$ & $0.94(0.64-1.37)$ & $1.75(1.19-2.58)^{* * *}$ \\
\hline \multicolumn{4}{|l|}{ Alcohol use } \\
\hline Yes & 1.00 & 1.00 & 1.00 \\
\hline
\end{tabular}

(Continued) 
Table 2 (Continued).

\begin{tabular}{|c|c|c|c|}
\hline \multirow[t]{2}{*}{ Variables } & Total & Men & Women \\
\hline & OR $(95 \% \mathrm{Cl})$ & OR $(95 \% \mathrm{Cl})$ & OR $(95 \% \mathrm{Cl})$ \\
\hline No & $1.34(0.85-2.11)$ & $1.30(0.78-2.15)$ & $1.24(0.39-3.99)$ \\
\hline \multicolumn{4}{|c|}{ Smoking status } \\
\hline Yes & 1.00 & 1.00 & 1.00 \\
\hline No & $0.78(0.46-1.32)$ & $0.87(0.50-1.53)$ & $0.45(0.05-3.80)$ \\
\hline \multicolumn{4}{|c|}{ Diet behavior } \\
\hline Yes & 1.00 & 1.00 & 1.00 \\
\hline No & I.0I $(0.73-1.40)$ & $0.73(0.45-1.18)$ & $1.44(0.91-2.30)$ \\
\hline \multicolumn{4}{|c|}{ Perceived environmental factors } \\
\hline \multicolumn{4}{|c|}{ Safety from crimes at night } \\
\hline Safe & $0.73(0.52-1.03)$ & $0.60(0.35-1.02)$ & $0.7 \mid(0.44-1.16)$ \\
\hline Not safe & 1.00 & 1.00 & 1.00 \\
\hline \multicolumn{4}{|c|}{ Traffic safety } \\
\hline Safe & $0.78(0.59-1.03)$ & $0.6 \mathrm{I}(0.4 \mathrm{I}-0.9 \mathrm{I})^{*}$ & I.0I $(0.67-\mid .5 I)$ \\
\hline Not safe & 1.00 & 1.00 & 1.00 \\
\hline
\end{tabular}

Notes: $* P<0.05, * * P<0.01, * * * P<0.001$.

Abbreviations: $\mathrm{OR}$, odds ratio; $\mathrm{Cl}$, confidence interval.

for depression are suggested to target older adults whose selfrated health status is low.

Apart from self-rated health status, certain other factors were associated with differences in depression between older men and women. Among personal factors, being older was negatively associated with depression in older men, whereas having hypertension was positively associated with depression in older women. Our data showed there was a slightly negative association between age and depression, especially in men. However, previous findings regarding the association between age and depression among older adults were mixed. ${ }^{10}$ Further studies using a larger sample size on the association of age and depression are needed. Consistent with our findings, previous studies showed that there was no association of hypertension with geriatric depression, ${ }^{38}$ except in women. ${ }^{6}$ Compared to men, women tended to spend more time in sitting behavior, ${ }^{39}$ which might be one of the causes of hypertension. Future studies are warranted to have a deeper understanding of the association between hypertension and depression by sex. The individual factors involved could be used to identify vulnerable individuals and increase the sensitivity of detection of geriatric depression.

Among behavioral factors, sufficient leisure time spent in walking was associated with a lower risk of depression in older men, whereas excessive TV viewing was associated with a higher risk of depression in older women.
The literature corroborates the findings of previous studies that less leisure time spent in walking is correlated with a higher risk of depression in men ${ }^{40}$ and lower total physical activity is correlated with a higher risk of depression in older adults overall. ${ }^{41}$ Several explanations have been suggested for interpreting the association between leisure time spent in walking and depression. One is the effect of distraction, namely that participating in physical activity during leisure time may divert negative thoughts and bad mood; another hypothesis is that social contact provides support, which improves mental health. ${ }^{42}$ In addition, TV viewing is a specific type of sedentary behavior associated with an increased risk of depression. ${ }^{43}$ Some possible explanations could elucidate the association between TV viewing and depression. First, excessive TV viewing may lead to a lack of social interaction, ${ }^{44}$ and poor sleep quality, ${ }^{45}$ which may result in depression. ${ }^{46,47}$ Second, TV viewing can displace or compress the time spent engaging in physical activity, which serves as a protective factor for depression. ${ }^{44,48}$ Alternatively, people who had some depressive symptoms were more likely to decrease their active behavior and increase sitting behavior. Future studies on health behavior and depression should consider sex differences.

In the present study, perceptions of safe neighborhood environments, particularly regarding traffic safety, were 
also found as associations with a lower risk of depression in older men. The perception of an unsafe environment is a chronic stressor and fears regarding neighborhood safety lead to insufficient social capital (ie, decreased willingness to interact with others) ${ }^{34}$ and reduced willingness to engage in outdoor physical activity. ${ }^{49}$ Previous studies showed men spent more time on physical activity than women. ${ }^{39}$ A perceived lack of environmental safety may indirectly attenuate the negative associations of physical activity with depression and somewhat increase the risk of depression among men. Furthermore, compared to women, men had a higher frequency to use motor vehicles in Taiwan $^{50}$ they may be more sensitive to traffic safety than crime safety. Future longitudinal research examining the associations between different environmental variables and depression by sex is necessary and highly encouraged.

In addition to strategies of behavioral change, the present study further highlights that changing environmental perceptions may be another strategy for depression prevention among older adults considering the sex differences. The present study had some limitations that should be noted. First, although the depression scale was dichotomous (mitigating vague responses) and specifically designed for older adults, this method is not always consistent with clinical diagnoses. Second, the measurements for personal, behavioral, and environmental factors were self-reported, so they might have been subject to recall bias or underreported because of the stigma attached to them. ${ }^{51}$ Furthermore, we did not control some potential confounders such as previous medical history and cognitive or functional impairment, which might have confounded the associations. Future related studies should take into account these variables. Third, the study was cross-sectional in design; thus, it could not prove causal relationships. Finally, the study might not be representative of the overall population, because the segment of the population without a household telephone (approximately $7.1 \%$ in 2015) was unreachable. ${ }^{52}$ In addition, selection bias might have caused the proportion of men aged 75 and above more than women and the prevalence of depression in the present study to be much higher than the official statistics. ${ }^{53}$

\section{Conclusion}

In addition to self-rated health, sex differences in the associations between factors and depression were observed in older adults. Encouraging men to spend more time on leisure walking and modifying a safe traffic environment while advocating women to spend less time on TV watching were associated with lower risks of depression among older adults.

\section{Abbreviations}

OR, odds ratio; GDS-4, Geriatric Depression Scale-4; BMI, body mass index; IPAQ, International Physical Activity Questionnaire; IPAQ-E, International Physical Activity Questionnaire Environmental Module; CIs, confidence intervals.

\section{Ethics approval and informed consent}

We obtained verbal informed consent from the participants. The study protocols were reviewed and approved by the Ethics Committee of National Taiwan Normal University (201605HM006).

\section{Data availability}

The data used during the present study are available from the corresponding authors upon reasonable request.

\section{Acknowledgment}

This research was supported by a grant from the University Research Park Project of Busan National University funded by Busan Institute of S\&T Evaluation and Planning.

\section{Author contributions}

All authors contributed towards data analysis, drafting and critically revising the paper, gave final approval of the version to be published, and agreed to be accountable for all aspects of the work.

\section{Disclosure}

The authors report no conflicts of interest in this work.

\section{References}

1. World Health Organization. Depression Fact Sheet; 2018. Available from: https://www.who.int/news-room/fact-sheets/detail/depression. Accessed August 2, 2019.

2. Greenberg PE, Fournier AA, Sisitsky T, Pike CT, Kessler RC. The economic burden of adults with major depressive disorder in the United States (2005 and 2010). J Clin Psychiatry. 2015;76(2):155162. doi: $10.4088 / \mathrm{JCP} .14 \mathrm{~m} 09298$

3. Luppa M, Sikorski C, Luck T, et al. Age- and gender-specific prevalence of depression in latest-life - systematic review and meta-analysis. $J$ Affect Disord. 2012;136(3):212-221. doi:10.1016/j.jad.2010.11.033

4. Lue BH, Chen LJ, Wu SC. Health, financial stresses, and life satisfaction affecting late-life depression among older adults: a nationwide, longitudinal survey in Taiwan. Arch Gerontol Geriatr. 2010;50:S34S38. doi:10.1016/S0167-4943(10)70010-8 
5. Van de Velde S, Bracke P, Levecque K. Gender differences in depression in 23 European countries. Cross-national variation in the gender gap in depression. Soc Sci Med. 2010;71(2):305-313. doi:10.1016/j.socscimed.2010.03.035

6. Wang JK, Su TP, Chou P. Sex differences in prevalence and risk indicators of geriatric depression: the Shih-Pai community-based survey. J Formos Med Assoc. 2010;109(5):345-353. doi:10.1016/S09296646(10)60062-9

7. Ministry of Interior of Taiwan, Department of Statistics. Population Statistics in 2018; 2018. Available from: http://statis.moi.gov.tw/ micst/stmain.jsp?sys=100. Accessed August 2, 2019.

8. Wang JJ. Prevalence and correlates of depressive symptoms in the elderly of rural communities in southern Taiwan. J Nurs Res. 2001;9(3):1-12.

9. Hu P, Adler NE, Goldman N, Weinstein M, Seeman TE. Relationship between subjective social status and measures of health in older Taiwanese persons. $J$ Am Geriatr Soc. 2005;53(3):483-488. doi:10.1111/j.1532-5415.2005.53169.x

10. Vink D, Aartsen MJ, Schoevers RA. Risk factors for anxiety and depression in the elderly: a review. J Affect Disord. 2008;106(12):29-44. doi:10.1016/j.jad.2007.06.005

11. Sallis JF, Owen N, Fisher E. Ecological models of health behavior. Health Behav. 2015;5:43-64.

12. World Health Organization. Active Ageing: A Policy Framework. Geneva: World Health Organization; 2002.

13. Meyer OL, Castro-Schilo L, Aguilar-Gaxiola S. Determinants of mental health and self-rated health: a model of socioeconomic status, neighborhood safety, and physical activity. Am J Public Health. 2014;104(9):1734-1741. doi:10.2105/AJPH.2014.302003

14. Wilson-Genderson M, Pruchno R. Effects of neighborhood violence and perceptions of neighborhood safety on depressive symptoms of older adults. Soc Sci Med. 2013;85:43-49. doi:10.1016/j. socscimed.2013.02.028

15. Toma A, Hamer M, Shankar A. Associations between neighborhood perceptions and mental well-being among older adults. Health Place. 2015;34:46-53. doi:10.1016/j.healthplace.2015.03.014

16. Ministry of Interior, Department of Statistics. Population Statistics in 2016. 2016; Available from: http://statis.moi.gov.tw/micst/stmain.jsp? sys=100. Accessed August 2, 2019.

17. D'Ath P, Katona P, Mullan E, Evans S, Katona C. Screening, detection and management of depression in elderly primary care attenders. I: the acceptability and performance of the 15 item Geriatric Depression Scale (GDS15) and the development of short versions. Fam Pract. 1994;11(3):260-266. doi:10.1093/fampra/11.3.260

18. Holtfreter K, Reisig MD, Turanovic JJ. Depression and infrequent participation in social activities among older adults: the moderating role of high-quality familial ties. Aging Ment Health. 2017;21 (4):379-388. doi:10.1080/13607863.2015.1099036

19. Chin W-C, Liou C-Y, Lee C-P, Chu C-L. Validation of five short versions of the geriatric depression scale in the elder population in Taiwan. Taiwan J Psychiatry. 2014;28(3):156-163.

20. Health Promotion Administration, Ministry of Health and Welfare. Body mass index test; 2016. Available from: http://health99.hpa.gov. tw/OnlinkHealth/Onlink BMI.aspx. Accessed August 2, 2019.

21. Hsueh MC, Liao Y, Chang SH. Associations of total and domainspecific sedentary time with type 2 diabetes in Taiwanese older adults. J Epidemiol. 2016;26(7):348-354. doi:10.2188/jea.JE20150095

22. Liao Y, Wang IT, Hsu HH, Chang SH. Perceived environmental and personal factors associated with walking and cycling for transportation in Taiwanese adults. Int J Environ Res Public Health. 2015;12 (2):2105-2119. doi:10.3390/ijerph120202105

23. Liou YM, Jwo CJ, Yao KG, Chiang LC, Huang LH. Selection of appropriate Chinese terms to represent intensity and types of physical activity terms for use in the Taiwan version of IPAQ. J Nurs Res. 2008;16(4):252-263.
24. Nelson ME, Rejeski WJ, Blair SN, et al. Physical activity and public health in older adults: recommendation from the American College of Sports Medicine and the American Heart Association. Med Sci Sports Exerc. 2007;39(8):1435-1445. doi:10.1249/mss.0b013e3180616aa2

25. World Health Organization. Global Recommendations on Physical Activity for Health. Geneva: World Health Orgnaization; 2010.

26. Hsueh MC, Liao Y, Chang SH. Perceived neighborhood and home environmental factors associated with television viewing among Taiwanese older adults. Int J Environ Res Public Health. 2016;13 (7):708. doi:10.3390/ijerph13121252

27. Bowman SA. Television-viewing characteristics of adults: correlations to eating practices and overweight and health status. Prev Chronic Dis. 2006;3(2):A38.

28. Dunstan DW, Salmon J, Owen N, et al. Associations of TV viewing and physical activity with the metabolic syndrome in Australian adults. Diabetologia. 2005;48(11):2254-2261. doi:10.1007/s00125-005-1963-4

29. Gazmararian J, Baker D, Parker R, Blazer DG. A multivariate analysis of factors associated with depression: evaluating the role of health literacy as a potential contributor. Arch Intern Med. 2000;160(21):3307-3314.

30. Weyerer S, Eifflaender-Gorfer S, Kohler L, et al. Prevalence and risk factors for depression in non-demented primary care attenders aged 75 years and older. J Affect Disord. 2008;111(2-3):153-163. doi:10.1016/j.jad.2008.02.008

31. McGrath-Hanna NK, Greene DM, Tavernier RJ, Bult-Ito A. Diet and mental health in the arctic: is diet an important risk factor for mental health in circumpolar peoples? - a review. Int J Circumpolar Health. 2003;62(3):228-241. doi:10.3402/ijch.v62i3.17560

32. Sallis JF, Bowles HR, Bauman A, et al. Neighborhood environments and physical activity among adults in 11 countries. Am J Prev Med. 2009;36(6):484-490. doi:10.1016/j.amepre.2009.01.031

33. Jitnarin N, Heinrich KM, Haddock CK, Hughey J, Berkel L, Poston WS. Neighborhood environment perceptions and the likelihood of smoking and alcohol use. Int J Environ Res Public Health. 2015;12 (1):784-799. doi:10.3390/ijerph120100784

34. Curry A, Latkin C, Davey-Rothwell M. Pathways to depression: the impact of neighborhood violent crime on inner-city residents in Baltimore, Maryland, USA. Soc Sci Med. 2008;67(1):23-30. doi:10.1016/j.socscimed.2008.03.007

35. Liao Y. Association of sociodemographic and perceived environmental factors with public bicycle use among Taiwanese urban adults. Int J Environ Res Public Health. 2016;13:3. doi:10.3390/ijerph13121252

36. de Beurs E, Beekman A, Geerlings S, Deeg D, Van Dyck R, Van Tilburg W. On becoming depressed or anxious in late life: similar vulnerability factors but different effects of stressful life events. $\mathrm{Br} J$ Psychiatry Suppl. 2001;179(5):426-431. doi:10.1192/bjp.179.5.426

37. Hybels CF, Blazer DG, Pieper CF. Toward a threshold for subthreshold depression: an analysis of correlates of depression by severity of symptoms using data from an elderly community sample. Gerontologist. 2001;41(3):357-365. doi:10.1093/geront/41.3.357

38. Long J, Duan G, Tian W, et al. Hypertension and risk of depression in the elderly: a meta-analysis of prospective cohort studies. J Hum Hypertens. 2015;29(8):478-482. doi:10.1038/jhh.2014.112

39. $\mathrm{Ku}$ PW, Fox KR, Chen LJ. Physical activity and depressive symptoms in Taiwanese older adults: a seven-year follow-up study. Prev Med. 2009;48(3):250-255.

40. Mikkelsen SS, Tolstrup JS, Flachs EM, Mortensen EL, Schnohr P, Flensborg-Madsen T. A cohort study of leisure time physical activity and depression. Prev Med. 2010;51(6):471-475. doi:10.1016/j. ypmed.2010.09.008

41. Strawbridge WJ, Deleger S, Roberts RE, Kaplan GA. Physical activity reduces the risk of subsequent depression for older adults. $\mathrm{Am} \mathrm{J}$ Epidemiol. 2002;156(4):328-334. doi:10.1093/aje/kwf047

42. Teychenne M, Ball K, Salmon J. Physical activity and likelihood of depression in adults: a review. Prev Med. 2008;46(5):397-411. doi:10.1016/j.ypmed.2008.01.009 
43. Primack BA, Swanier B, Georgiopoulos AM, Land SR, Fine MJ. Association between media use in adolescence and depression in young adulthood: a longitudinal study. Arch Gen Psychiatry. 2009;66(2):181-188. doi:10.1001/archgenpsychiatry. 2008.532

44. Teychenne M, Ball K, Salmon J. Sedentary behavior and depression among adults: a review. Int J Behav Med. 2010;17(4):246-254. doi:10.1007/s12529-010-9075-z

45. Lewis O, Odeyemi Y, Joseph V, Mehari A, Gillum RF. Screen hours and sleep symptoms: the US national health and nutrition examination survey. Fam Community Health. 2017;40(3):231-235. doi:10.1097/FCH.0000000000000150

46. Szklo-Coxe M, Young T, Peppard PE, Finn LA, Benca RM. Prospective associations of insomnia markers and symptoms with depression. Am J Epidemiol. 2010;171(6):709-720. doi:10.1093/aje/ kwp454

47. Horowitz A, Reinhardt JP, Boerner K, Travis LA. The influence of health, social support quality and rehabilitation on depression among disabled elders. Aging Ment Health. 2003;7(5):342-350. doi:10.1080/ 1360786031000150739
48. de Wit L, van Straten A, Lamers F, Cuijpers P, Penninx B. Are sedentary television watching and computer use behaviors associated with anxiety and depressive disorders? Psychiatry Res. 2011;186(23):239-243. doi:10.1016/j.psychres.2010.07.003

49. Foster S, Giles-Corti B. The built environment, neighborhood crime and constrained physical activity: an exploration of inconsistent findings. Prev Med. 2008;47(3):241-251. doi:10.1016/j.ypmed.2008.03.017

50. Lin C-Y, Liao Y, Park JH. Association of motorcycle use with risk of overweight in Taiwanese urban adults. Int $J$ Environ Res Public Health. 2017;14:4. doi:10.3390/ijerph14040410

51. Hallal PC, Gomez LF, Parra DC, et al. Lessons learned after 10 years of IPAQ use in Brazil and Colombia. J Phys Act Health. 2010;7 (Suppl 2):S259-S264. doi:10.1123/jpah.7.s2.s259

52. Directorate General of Budget, Accounting and Statistics, Taiwan. Report on the Survey of Family Income and Expendture; 2015. Available from: http://www1.stat.gov.tw/mp.asp?mp=3. Accessed August 2, 2019.

53. Ministry of Health and Welfare; Health Promotion Administration. 2011 Taiwan longitudinal study on aging survey report. In: Taiwan Aging Study Series, No.12. Taipei, Taiwan: Health Promotion Administration, Ministry of Health and Welfare of Taiwan; 2011.
Psychology Research and Behavior Management

\section{Publish your work in this journal}

Psychology Research and Behavior Management is an international, peer-reviewed, open access journal focusing on the science of psychology and its application in behavior management to develop improved outcomes in the clinical, educational, sports and business arenas. Specific topics covered in the journal include: Neuroscience, memory and decision making; Behavior modification and management; Clinical

\section{Dovepress}

applications; Business and sports performance management; Social and developmental studies; Animal studies. The manuscript management system is completely online and includes a very quick and fair peer-review system, which is all easy to use. Visit http://www. dovepress.com/testimonials.php to read real quotes from published authors. 